\title{
ELECTRIC VEHICLES AND TRAFFIC RELATED POLLUTION REDUCTION: A SIMULATION MODEL FOR HAMILTON, ONTARIO, CANADA
}

\author{
PAPARGYRI E. ${ }^{1}$ \\ KANAROGLOU P.S. ${ }^{2}$ \\ PHOTIS Y.N. ${ }^{1, *}$
}

\author{
${ }^{1}$ School of Rural and Survey Engineering \\ National Technical University of Athens \\ Zographou Campus, Athens, 157 73, Greece \\ ${ }^{2}$ Center for Spatial Analysis (CSpA), School of Geography and Earth Sciences \\ McMaster University, Hamilton, Ontario L8S-4K1, Canada
}

Received: 02/02/2013

Accepted: 29/04/2014

*to whom all correspondence should be addressed:

Available online: 07/05/2014

e-mail:yphotis@mail.ntua.gr

\begin{abstract}
This paper analyzes the potential contribution of electric vehicles in greenhouse gas (GHG) emissions reduction over the next decade following a simulation procedure. Emissions were assessed through a stepwise methodological approach at the transportation link level in the Hamilton Census Metropolitan Area (CMA). Firstly, different EV market penetration scenarios were introduced and compared to the base case scenario. Following these, the spatial distribution patterns of EVs were predicted using vehicle registration data for the Hamilton CMA as well as socioeconomic data obtained from census records. Properly modified matrices were used as input into our traffic simulation model in order to assign traffic on the network and estimate volumes for each of the links. To this end MOBILE $6.2 C^{1}$ was customized so as to compute the emission factors. The hourly emissions of each link were mapped in a GIS environment. We conclude that different utilization patterns result to varying spatial distributions of traffic related emissions in the links and even a modest adoption of EV technology may lead to their significant reduction.
\end{abstract}

Keywords: Electric mobility, electric vehicles, traffic emissions, regression, simulation model, Hamilton CMA.

\section{Objectives}

In Canada, the transportation sector accounts for $75 \%$ of emitted carbon monoxide (CO), $67 \%$ of nitrogen oxides $\left(\mathrm{NO}_{x}\right), 49 \%$ of non methane hydrocarbons $(\mathrm{HC})$ and $25 \%$ of carbon dioxide $\left(\mathrm{CO}_{2}\right)(\mathrm{OECD}$, 2007).

The electrification of road transport has received significant attention in the past two decades as a step towards sustainability, helping to further mitigate localized vehicle emissions. However, the actual amount of emissions created per kilometer driven depends on the electricity generation mix of the grid from which the battery is charged (Peterson et al., 2011). For example, electricity from nuclear, hydro, solar, or wind-powered plants emits very low amounts of air pollutants. Ontario gets most of its electricity from nuclear power (49\%). The remainder comes from a mix of natural gas (26\%), hydroelectric (18\%), coal (5\%) and wind (2\%) according to Canadian Nuclear Society (2013).

\footnotetext{
${ }^{1}$ MOBILE $6.2 \mathrm{C}$ is a version of MOBILE 6 originally developed by U.S Environmental Protection Agency to reflect the vehicle fleet and it was then modified by Environment Canada to embrace Canadian conditions.
}

Papargyri E., Kanaroglou P.S. and Photis Y.N. (2014), Electric vehicles and traffic related pollution reduction: A simulation model for Hamilton, Ontario, Canada, Global NEST Journal, 16(4), 753-761. 
This paper offers insight on the potential contribution of electric vehicles in GHG emissions reduction over the next decade. Recent research has focused on evaluating the potential demand and acceptance from users (Brady and O' Mahony, 2011), the willingness to pay for alternative fuel vehicles (Ito et al., 2011), the reliability of battery systems (Earley et al., 2011) and the energy demand per vehicle (Bueno, 2012). Less has been done to assess the emissions produced after the introduction of EVs. By applying different adoption rates of EVs combined with a set of integrated simulation models (Mobile 6.2C, TRAFFIC, LINK EMISSIONS) we aim to evaluate the spatial distribution of emissions in the Hamilton Census Metropolitan Area.

\section{Background}

In Canada, greenhouse gas (GHG) emissions from the transportation sector grew by $24 \%$ between 1990 and 2008 (Canada's Action, 2010). In this respect, reducing emissions from this sector will constitute a major step towards sustainability. Towards this end, automobile manufacturers introduce EVs at an increasing pace. These are associated with high efficiency, low operation costs and zero tailpipe emissions. To support this action, Ontario's government has announced a number of incentives to assist individuals, businesses and organizations in adopting clean and efficient vehicles (Ministry of Transportation, 2010).

Many researchers have attempted to model and predict the EVs market uptake (Perujo and Ciuffo, 2010; Cunningham, 2009). About $40 \%$ of the analysts expect EVs market uptake range to be between $2 \%$ and $5 \%$, almost $30 \%$ suggest that EVs market penetration will fall between $5 \%-10 \%$ and the rest forecast a market share up to $25 \%$ in 2020 . Estimates are based on differing assumptions and simulation models. Most of the studies attempt to assess the advantages of EVs deployment and plenty of them report that a net abatement in GHG emissions can be achieved by replacing internal combustion engine vehicles with EVs (Thiel et al., 2010). Greater $\mathrm{CO}_{2}$ reduction could be expected in the future if the generated electricity derives from renewable sources (Ji et al., 2011).

Since any driver's decision-making with respect to buying an EV can be considered, if not identical, similar to the standard vehicle purchase process, studies dealing with car ownership were also assessed. In this framework, according to research, which focuses on capturing potential EVs buyers characteristics, these seem to be more or less similar to the characteristics of HEVs buyers (Cunningham, 2009; Perujo and Ciuffo 2010). More specifically, household income significantly influences car ownership in general and EV ownership in particular. The type of dwelling is important as well. Detached and semi-detached houses usually come with available parking and extra space suitable to locate the charging infrastructure that EVs need. The level of education of members in a household consistently appears to influence EVs adoption because of its pairing with increased environmental sensitivity for GHG reduction and willingness to adopt new technologies in order to mitigate costs associated with conventional vehicles (Stuben and Sterman, 2008). Other important variables influencing EVs possession are: household structure and age (Chu, 2002), number of working adults (Potoglou and Kanaroglou, 2008) and residential location (Bento et al., 2005).

\section{Methods}

\subsection{Study area and data}

The effect of EVs on traffic related pollution is assessed at the transportation link level in the Hamilton Census Metropolitan Area (CMA) - located between the US border at Niagara Falls and Toronto, on the western shore of Lake Ontario - excluding Grimsby. The area is divided into 172 census tracts and 223 Traffic Analysis Zones (TAZs). The 223 TAZs are connected through 831 network links. These links include 223 pseudo links which connect the centroid of each TAZ to the main network of the Hamilton CMA.

The data used for this study were derived from three sources. The first set of data includes demographic and socioeconomic characteristics of people at the census tract level, taken from the 2006 Canadian 
Census and converted, when needed, into proportional data. Vehicle registration data were obtained from POLK (www.polk.com). These data contained information regarding the vehicle type, fuel, model year as well as Gross Vehicle Weight Rating (GVWR) for every passenger car registered in the study area. Finally, Origin-Destination (OD) matrices were derived from household travel surveys (TTS, 2006).

\subsection{Methodological framework}

In this section the steps followed in our analysis are presented in the order that were implemented. Firstly, we used a combination of data from Polk and the Census in a regression analysis framework to determine the socioeconomic factors that influence EV ownership and to derive weights that determine the spatial distribution of EVs. On the second step, the simulation models used for this study didn't include EVs to their vehicle classification and no previous data on travel patterns existed for EVs, therefore, O-D matrices modification was needed to incorporate the new vehicle. By applying the weights, we modified the O-D matrices for 2021 and using user-equilibrium traffic assignment algorithms we assigned trips to the road links of the network. On the third stage, we estimated the emission factors for the Hamilton CMA, which we combined with the traffic volume outputs in order to estimate the traffic related emissions. Finally, the contribution of EVs to reduce GHG emissions was evaluated.

\section{Results and discussion}

Since very few EVs were registered in the study area, the regression models were estimated based on current HEVs distribution. Three EV market penetration scenarios were introduced and compared to the base case scenario where no action took place. The first hypothesis -Scenario 1-constituted the most optimistic scenario, describing the distribution pattern after the introduction of $10 \%$ of EVs. Scenario 2 referred to moderate market growth of EVs which will result in attaining 5\% (20950 vehicles) of market share, whilst under the conservative scenario - Scenario 3- EVs will capture $2 \%$ of total vehicle fleet (8380 vehicles) by 2021.

The negative binomial regression model (NBRM) was preferred for our analysis, since it is widely considered as a standard when analyzing count data. The outputs from the regression analysis were three different distributions of EVs. Three models were proposed combining different socioeconomic characteristics that are argued to influence EVs ownership according to Curtin's et al. (2009) and Potoglou and Kanaroglou (2008). Each model included the minimum number of variables that adequately described the data, ensuring that no important variable was omitted from the equations avoiding in this manner the cause of bias in the estimates of the remaining coefficients.

The estimation results of the NBRM are presented in Table 1 . The models show a reasonable overall statistical fit, as indicated by their respective $R^{2}$ statistics. Additionally, the signs of the exploratory variables are consistent with our a priori expectations and in accordance with the literature.

In order to assign the traffic volumes to the road links of the network, TRAFFIC, a GIS-based Stochastic User Equilibrium (SUE) traffic assignment program was used. TRAFFIC is designed to accommodate five main vehicle classes [light duty passenger vehicles (LDPV), light duty commercial vehicles (LDCV), medium duty vehicles (MDV), heavy duty vehicles (HDV) and Buses] (CSpA, 2009) and utilizes O-D matrices as input to simulate traffic flows in an area. In order to include EVs in our mode, we combined LDPV and LDCV into one class namely, light duty vehicles (LDV), considering that they both have the same passenger car equivalency (PCE) values as well as no restrictions on the use of road network links. The new EVs distribution patterns stemming from the regression models were used in the O-D matrices manipulation process.

The emission factors for Hamilton CMA were calculated in MOBILE6.2C and were converted to zero values for the LDV vehicle class. The link flows were then combined with the emission factors to produce estimates of $\mathrm{HC}, \mathrm{CO}, \mathrm{NO}_{x}$ and $\mathrm{CO}_{2}$ emissions at an aggregate and disaggregate level. These estimates relate to average speed and air temperature as well as a set of vehicle-fleet characteristics. The LINK 
EMISSIONS program was then used in order to extract the estimated in grams emissions to a tabular format.

Table 1. Summary of NBRM- based EV distribution model

\begin{tabular}{|c|c|c|c|c|c|c|c|c|c|c|c|}
\hline \multicolumn{4}{|c|}{ Model 1} & \multicolumn{4}{|c|}{ Model 2} & \multicolumn{4}{|c|}{ Model 3} \\
\hline Parameters & B & $\begin{array}{c}\text { St. } \\
\text { Error }\end{array}$ & $\begin{array}{c}p- \\
\text { value }\end{array}$ & $\begin{array}{c}\text { Parameter } \\
\mathrm{s}\end{array}$ & B & $\begin{array}{c}\text { St.Err } \\
\text { or }\end{array}$ & $\begin{array}{c}p- \\
\text { value }\end{array}$ & $\begin{array}{c}\text { Parameter } \\
\mathrm{s}\end{array}$ & B & $\begin{array}{c}\text { St.Err } \\
\text { or }\end{array}$ & $\begin{array}{c}\mathrm{p}- \\
\text { value }\end{array}$ \\
\hline Intercept & 3.19 & 0.73 & 0 & Intercept & 4.17 & 0.829 & 0 & Intercept & 6.35 & 1.57 & 0 \\
\hline LEDU & -2.04 & 0.02 & 0.006 & LEDU & $\begin{array}{c}- \\
3.03 \\
\end{array}$ & 0.016 & 0.051 & ODWE & 1.02 & 0.01 & 0.001 \\
\hline$[\mathrm{INC}=1]$ & -1.78 & 0.35 & 0 & {$[\mathrm{INC}=1]$} & $\begin{array}{c}- \\
0.98 \\
\end{array}$ & 0.403 & 0.015 & DDWE & $\begin{array}{c}- \\
0.96 \\
\end{array}$ & 0.02 & 0.005 \\
\hline$[\mathrm{INC}=2]$ & -0.93 & 0.2 & 0 & [INC=2] & $\begin{array}{c}- \\
0.41\end{array}$ & 0.233 & 0.081 & LEDU & $\begin{array}{c}- \\
2.76 \\
\end{array}$ & 0.02 & 0 \\
\hline$[\mathrm{INC}=3]$ & $0^{a}$ & $\cdot$ & . & [INC=3] & 0 & $\cdot$ & . & NPPCF & $\begin{array}{c}- \\
0.85 \\
\end{array}$ & 0.46 & 0.066 \\
\hline SEN & 1.06 & 0.01 & 0 & SINPAR & $\begin{array}{c}- \\
1.53 \\
\end{array}$ & 0.001 & 0.048 & & & & \\
\hline PWSCT & 2.3 & 0.01 & 0.001 & CWCHILD & 2.16 & 0.001 & 0.049 & & & & \\
\hline & & & & UNEMP & -3.3 & 0.109 & 0.002 & & & & \\
\hline
\end{tabular}

\begin{tabular}{cccc}
\hline & Model 1 & Model 2 & Model 3 \\
\hline Chi-square & 192.238 & 188.511 & 199.511 \\
\hline $\mathrm{p}$-value & 0.000 & 0.000 & 0.000 \\
\hline $\mathrm{LL}\left(\beta_{\mathrm{u}}\right)^{2}$ & -126.742 & -135.105 & -126.79 \\
\hline $\mathrm{LL}\left(\beta_{\mathrm{R}}\right)^{3}$ & -222.861 & -229.361 & -226.546 \\
\hline Pseudo R & 0.431296 & 0.410949 & 0.440333 \\
\hline $\mathrm{R}^{2}$ & 0.89 & 0.88 & 0.91
\end{tabular}

Emission estimates were available for 24 hours and 365 days of years 2006 and 2021 but only the morning and rush hour data (8am and $5 \mathrm{pm}$ ) for January $1^{\text {st }}$ and July $1^{\text {st }}$ were selected to evaluate the potential reduction in emissions estimates. The results of each model were compared to the results of the 'Business as Usual' (BaU) scenario.

\subsection{Aggregate level results}

We summarize results for the entire study area in Table 2. The table displays the percent change in emission estimates per pollutant and for all the models that were created with respect to the different EV penetration rates. Models1_1-1_3 refer to the results of the models when the $1^{\text {st }}$ Scenario is applied and respectively Models2_1-2_3 to the $2^{\text {nd }}$ Scenario and Models3_1-3_3 to the $3^{\text {rd }}$. Aggregate emissions are the summations of emission estimates across all links in the road network. Although the reduction of traffic emissions is evident across all scenarios, slight changes are also observed between the different distribution models. For example, Models 2 and 3 show more similar percentage changes for all pollutants than with Model 1.

An interesting and in some respect, unexpected finding is that the percent abatement in $\mathrm{HC}$ and $\mathrm{CO}$ emissions in the morning for both January and July and the percent of EVs in the total fleet do not follow a linear trend. This fact can be explained by the high traffic volume observed that time of the day and the high $\mathrm{HC}$ and $\mathrm{CO}$ emissions produced at low speeds. While in the evening, as speeds are higher, the calculated $\mathrm{HC}$ and $\mathrm{CO}$ emissions change is lower.

\footnotetext{
${ }^{2}$ Unrestricted Log likelihood

${ }^{3}$ Restricted log likelihood
} 
Table 2. Percent aggregate emissions reduction compared to rush hours BAU (Jan $1^{\text {st }} \&$ July $1^{\text {st }}$ )

\begin{tabular}{|c|c|c|c|c|c|c|c|c|}
\hline & \multicolumn{8}{|c|}{ January 1st } \\
\hline & \multicolumn{4}{|c|}{$8 a m$} & \multicolumn{4}{|c|}{$5 p m$} \\
\hline & $\mathrm{HC}$ & $\mathrm{CO}$ & $\mathrm{NO}_{\mathrm{x}}$ & $\mathrm{CO}_{2}$ & $\mathrm{HC}$ & $\mathrm{CO}$ & $\mathrm{NO}_{\mathrm{x}}$ & $\mathrm{CO}_{2}$ \\
\hline Model1_1 & $-48.58 \%$ & $-38.69 \%$ & $-13.41 \%$ & $-10.63 \%$ & $-12.17 \%$ & $-12.04 \%$ & $-11.47 \%$ & $-11.62 \%$ \\
\hline Model1_2 & $-47.27 \%$ & $-39.02 \%$ & $-14.89 \%$ & $-10.63 \%$ & $-11.56 \%$ & $-11.49 \%$ & $-11.10 \%$ & $-11.31 \%$ \\
\hline Model1_3 & $-49.20 \%$ & $-39.36 \%$ & $-14.13 \%$ & $-11.39 \%$ & $-18.80 \%$ & $-16.69 \%$ & $-13.16 \%$ & $-13.06 \%$ \\
\hline Model2_1 & $-6.05 \%$ & $-5.89 \%$ & $-5.03 \%$ & $-5.15 \%$ & $-5.92 \%$ & $-5.85 \%$ & $-5.57 \%$ & $-5.64 \%$ \\
\hline Model2_2 & $-5.84 \%$ & $-5.75 \%$ & $-4.97 \%$ & $-5.13 \%$ & $-5.63 \%$ & $-5.59 \%$ & $-5.38 \%$ & $-5.48 \%$ \\
\hline Model2_3 & $-6.80 \%$ & $-6.53 \%$ & $-5.42 \%$ & $-5.54 \%$ & $-6.70 \%$ & $-6.61 \%$ & $-6.27 \%$ & $-6.35 \%$ \\
\hline Model3_1 & $-2.22 \%$ & $-2.16 \%$ & $-1.81 \%$ & $-1.85 \%$ & $-2.14 \%$ & $-2.12 \%$ & $-2.02 \%$ & $-2.04 \%$ \\
\hline Model3_2 & $-2.09 \%$ & $-2.06 \%$ & $-1.80 \%$ & $-1.85 \%$ & $-2.02 \%$ & $-2.01 \%$ & $-1.94 \%$ & $-1.98 \%$ \\
\hline Model3_3 & $-2.41 \%$ & $-2.34 \%$ & $-1.96 \%$ & $-2.00 \%$ & $-2.46 \%$ & $-2.43 \%$ & $-2.30 \%$ & $-2.33 \%$ \\
\hline
\end{tabular}

\begin{tabular}{|c|c|c|c|c|c|c|c|c|}
\hline & & & & & uly 1st & & & \\
\hline & & & & & & & $5 p m$ & \\
\hline & $\mathrm{HC}$ & $\mathrm{CO}$ & $\mathrm{NO}_{\mathrm{x}}$ & $\mathrm{CO}_{2}$ & $\mathrm{HC}$ & $\mathrm{CO}$ & $\mathrm{NO}_{\mathrm{x}}$ & $\mathrm{CO}_{2}$ \\
\hline Model1_1 & $-52.32 \%$ & $-38.75 \%$ & $-12.92 \%$ & $-10.63 \%$ & $-12.24 \%$ & $-12.03 \%$ & $-11.31 \%$ & $-11.62 \%$ \\
\hline Model1_2 & $-51.03 \%$ & $-39.20 \%$ & $-14.60 \%$ & $-10.63 \%$ & $-11.57 \%$ & $-11.48 \%$ & $-14.44 \%$ & $-11.32 \%$ \\
\hline Model1_3 & $-52.93 \%$ & $-39.42 \%$ & $-13.62 \%$ & $-11.39 \%$ & $-20.02 \%$ & $-16.68 \%$ & $-13.01 \%$ & $-13.05 \%$ \\
\hline Model2_1 & $-6.12 \%$ & $-5.88 \%$ & $-4.89 \%$ & $-5.15 \%$ & $-5.96 \%$ & $-5.84 \%$ & $-5.49 \%$ & $-5.63 \%$ \\
\hline Model2_2 & $-5.91 \%$ & $-5.73 \%$ & $-4.82 \%$ & $-5.13 \%$ & $-5.64 \%$ & $-5.58 \%$ & $-5.31 \%$ & $-5.48 \%$ \\
\hline Model2_3 & $-6.90 \%$ & $-6.52 \%$ & $-5.26 \%$ & $-5.54 \%$ & $-6.75 \%$ & $-6.60 \%$ & $-6.19 \%$ & $-6.35 \%$ \\
\hline Model3_1 & $-2.25 \%$ & $-2.15 \%$ & $-1.76 \%$ & $-1.85 \%$ & $-2.15 \%$ & $-2.12 \%$ & $-1.99 \%$ & $-2.04 \%$ \\
\hline Model3_2 & $-2.10 \%$ & $-2.05 \%$ & $-1.74 \%$ & $-1.85 \%$ & $-2.02 \%$ & $-2.01 \%$ & $-1.91 \%$ & $-1.98 \%$ \\
\hline Model3_3 & $-2.45 \%$ & $-2.34 \%$ & $-1.90 \%$ & $-2.00 \%$ & $-2.48 \%$ & $-2.43 \%$ & $-2.27 \%$ & $-2.33 \%$ \\
\hline
\end{tabular}

While for $\mathrm{HC}$ and $\mathrm{CO}$ the emission factors raise as average link speed decreases, NOx emission factors tend to initially slightly decrease with speed, but then remain stable until about $30 \mathrm{mph}$, increasing with speed from then on. It is deduced that even a modest adoption of EV technology may lead to significant reduction in traffic emissions.

\subsection{Results at the link level}

This section is focused on the spatial concentration of emissions through a selected set of figures. The volume of emissions was normalized with regard to the length of links in order to be comparable. Figure 2 depicts the spatial pattern of $\mathrm{HC}$ emissions in the BAU scenario in 2021.

The links with the highest traffic emissions per kilometer included sections of QEW in Burlington, Hwy 403, Main St West, King St West and major highways a fact which is explained by the high volume of traffic as well as high vehicle flow in these specific roads during rush hours.

Due to space restrictions, $\mathrm{HC}$ emissions for a $10 \%$ EVs market uptake were selected to be presented in this paper. To compare the emissions produced by each model three ratios were obtained, dividing emissions from each model by the emissions of the BAU Scenario. Values close to 1 depict slight change in $\mathrm{HC}$ emissions while values between 0.8 and 0.9 illustrate a decrease and values less than 0.8 represent a massive $\mathrm{HC}$ emissions abatement. 


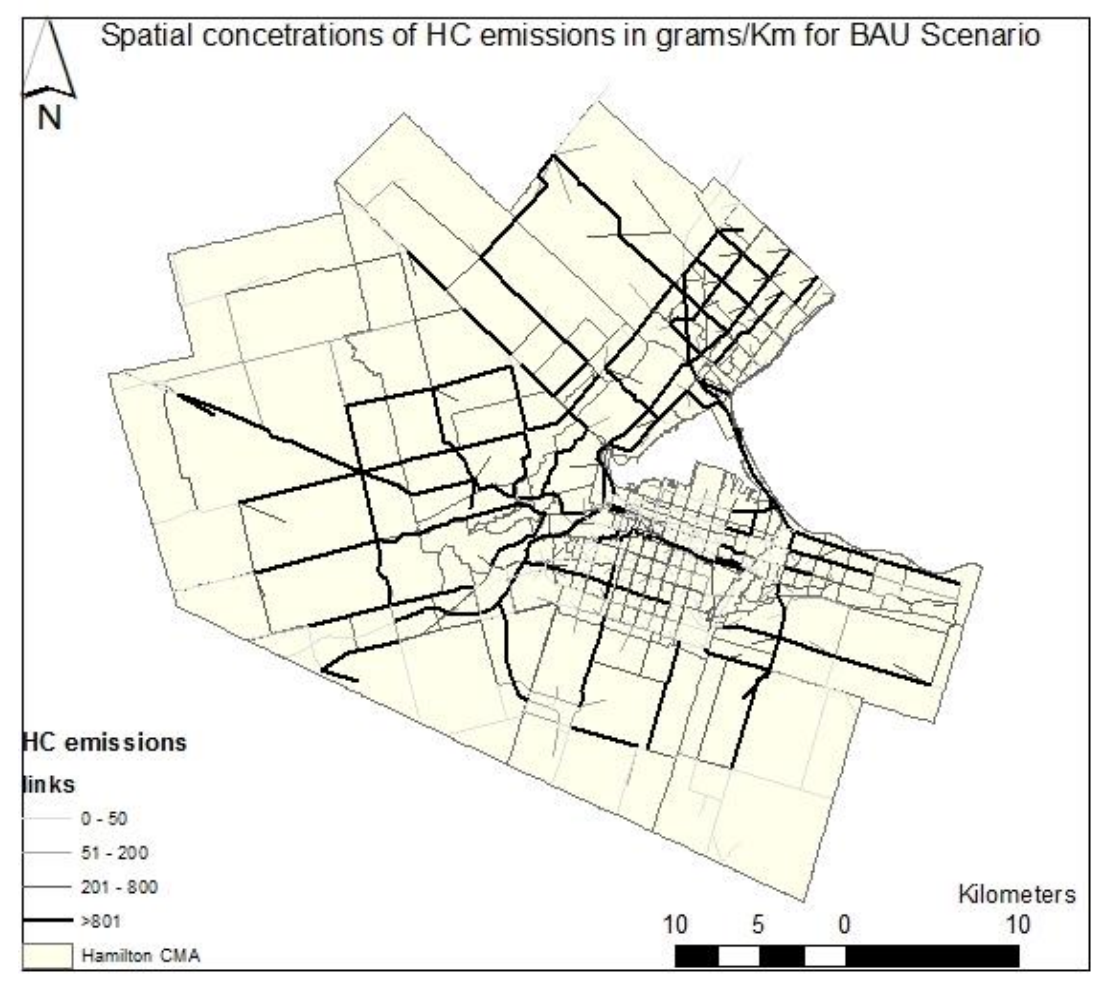

Figure 1. BAU Scenario - HC emissions in 2021

The following table displays both the number of links falling in each category and the change percentage. Model 3 is the model that appears to influence mostly the emissions produced as $46 \%$ of the links correspond to the second class and present a significant decrease in emissions.

Table 3. Classification of calculated ratios

\begin{tabular}{|c|c|c|c|}
\hline \multirow{2}{*}{ classes } & \multicolumn{3}{|c|}{ number of links/percentage } \\
\hline & Model 1 & Model 2 & Model 3 \\
\hline $0-0.8$ & & & \\
\hline $0.8-0.9$ & & & \\
\hline $0.9-1.0$ & 18 & 05 & 69 \\
\hline
\end{tabular}

The spatial variation of the three ratios is evident in Figure 3, which illustrates the emissions changes hotspots with regard to the BAU scenario. Two main 'hot-spot' areas of maximum change compared to the BAU scenario can be identified in the HC emissions map below.

The first one is evident across all three models and is located at Burlington city including major highways. These highways constitute main routes to and from the city of Toronto, a significant employment centre for Hamilton's residents. The second most important change occurs at Stoney Creek and it is observed only in the second model. On the other hand and across all models, trivial change compared to the BAU scenario is depicted in the core of the city of Hamilton. 


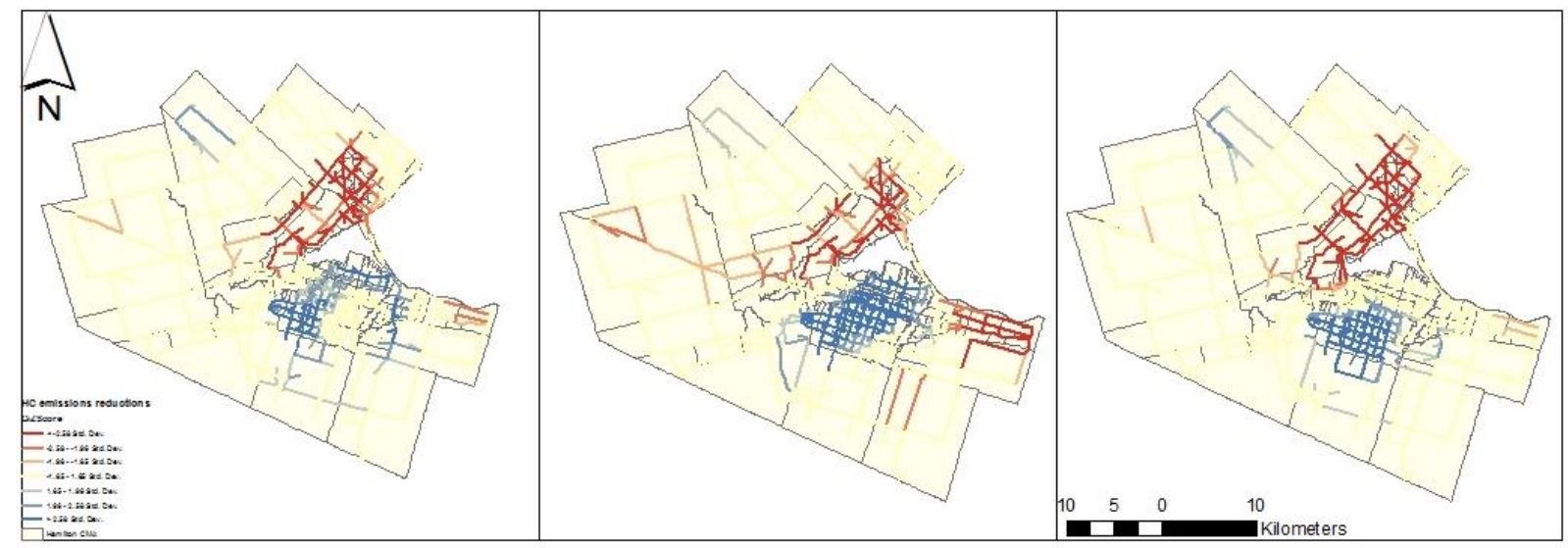

Figure 2. $\mathrm{HC}$ emissions fluctuation hotspots at the link level for models 1, 2 and 3 respectively

The next figure illustrates the spatial pattern of $\mathrm{HC}$ emissions reductions for each model and for the Optimistic Scenario. Five classes were created to accommodate the change in emissions percent.

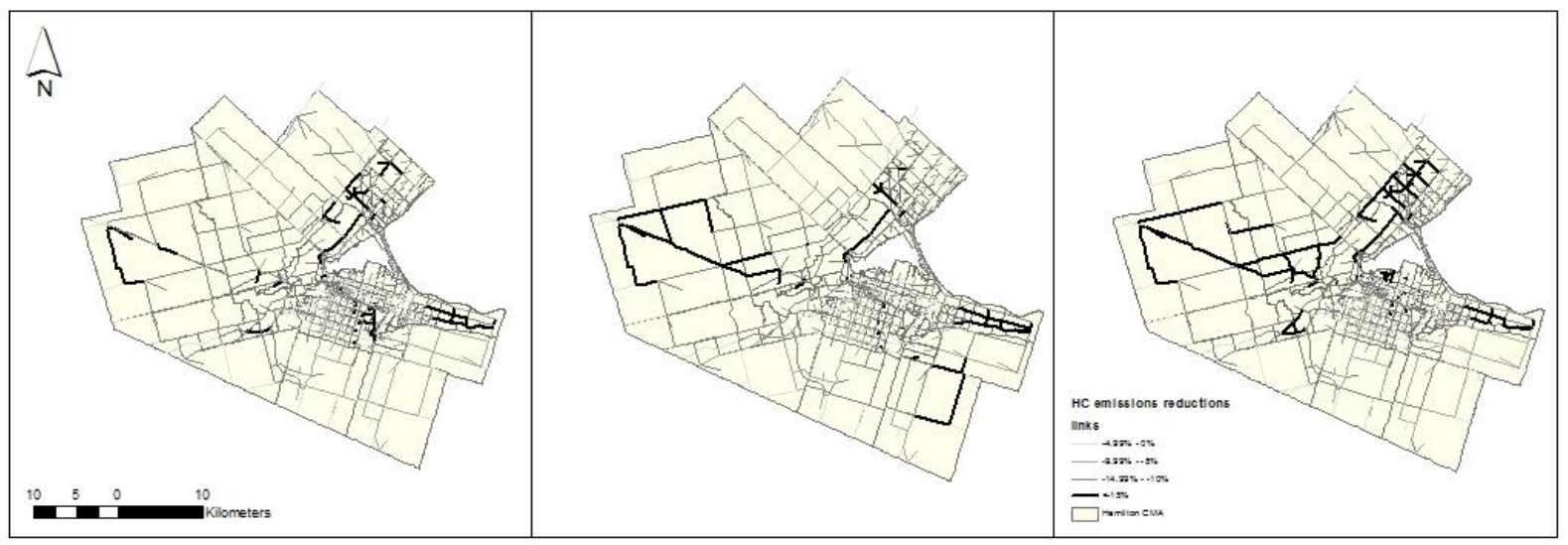

Figure 3. $\mathrm{HC}$ emissions reduction levels for Model 1, Model 2 and Model 3 respectively

The greatest reductions can be observed in the study area's major highways. With respect to the rest of the links, differing distribution patterns resulted to spatially varying traffic related emissions allocation.

\section{Conclusions}

In this paper, a methodological approach for the assessment of the contribution of EVs to traffic related emissions reduction within urban areas has been presented. We argue that although, the proposed framework is tested to the Hamilton CMA, it can have a wider applicability. Some of the main findings of this work are that different utilization patterns result to varying spatial distributions of traffic related emissions in the links and even a modest adoption of EV technology may lead to their significant reduction. The contribution of EVs to $\mathrm{HC}, \mathrm{CO}, \mathrm{NO}_{x}$ and $\mathrm{CO}_{2}$ emissions reduction has been addressed at the aggregate level; for the links disaggregate level we presented results only for $\mathrm{HC}$ emissions. It should be noted however, that although these results can be considered encouraging, they were based on the assumption that the electricity generated to charge the vehicles is derived from renewable sources. Hence, the final cost - benefit analysis rests on whether renewable resources are used to generate the increased electricity demand.

A recommendation that can be made with respect to future work is to develop more pragmatic and thus more complex market penetration scenarios based on the analysis of data collected through stated preference surveys. Such surveys, could cover inter and intra-regional flows by vehicle type. In that case, scenarios should also embed improvements in the characteristics of EVs (especially the range), a 
spatially more dispersed network of charging stations as well as government policy incentives towards further adoption of EVs.

\section{References}

Bento A.M., CropperM.L., Mobarak A.M. and Vinha K. (2005), The Impact of Urban Spatial Structure on Travel Demand in the United States, Review of Economic and Statistics, 87(3), 466-478.

Brady J., O'Mahony M. (2011), Travel to work in Dublin. The potential impacts of electric vehicles on climate change and urban air quality, Transportation Research Part D: Transport and Environment, 16(2), 188-193.

Bueno G. (2012), Analysis of scenarios for the reduction of energy consumption and GHG emissions in transport in the Basque Country, Renewable and Sustainable Energy Reviews, 16(4), 1988-1998.

Canada's Action. (2010). Canada's Action on Climate Change. Retrieved 2012 17-12 from Governement of Canada: http://www.climatechange.gc.ca/default.asp?lang=En\&n=97C0E131-1

Canadian Nuclear Society. (2013), Electricity Sources. Retrieved 2013 6-2 from http://media.cnssnc.ca/ontarioelectricity/ontarioelectricity.html

Chu Y.L. (2002), Automobile Ownership Analysis Using Ordered Probit Models, Transportation Research Record, 1805, pp. 60-67.

CSpA. (2009). Mobile Emission Estimates for Hamilton, Ontario, Canada. Hamilton: Mc Master University.

Cunningham J. (2009). An Analysis of Battery Electric Vehicle Production Projections. Massachusetts: MIT.

Curtin R., Shrago Y. and Mikkelsen J. (2009). Plug-in Hybrid Electric Vehicles. Michigan: University of Michigan Transportation Research Institute.

Earley R., Kang L., An F. and Green-Weiskel L. (2011). Electric vehicles in the context of sustainable development in China. Commission on Sustainable Development. New York: United Nations Department of Economic and Social Affairs.

https://www.polk.com, Access date: 25/01/2013

Ito N., T. K. (2011), Willingness to pay for the infrastructure investments for alternative fuel vehicles. Japan: Policy Studies of Environment and Economy.

Ji S., Cherry C., Bechle M., Wu Y. and Marshall J. (2011), Electric Vehicles in China: Emissions and Health Impacts, Environmental Science and Technology, 46, pp. 2018-2024.

Ministry of Transportation. (2010). A plan for a Greener Ontario, Retrieved 20/10/2012 from Ontario Ministry of Transportation: http://www.mto.gov.on.ca/english/dandv/vehicle/electric/plan-greener-ontario/index.shtml

OECD. (2007), Environmental Data, Compendium, Paris: OECD.

Perujo A. and Ciuffo B. (2010), The introduction of electric vehicles in the private fleet: Potential impact on the electric supply system and on the environment. A case study for the Province of Milan, Italy. Energy Policy, 38, pp. 4549-4561.

Peterson S.B., Whitacre J.F. and Apt J. (2011), Net Air Emissions from Electric Vehicles: The Effect of Carbon Price and Charging Strategies, Environmental Science and Technology, 45 (5), pp.1792-1797

Potoglou D. and Kanaroglou P. (2008). Modelling car ownership in urban areas:a case study of Hamilton, Canada, Journal of Transport Geography, 16(1), 42-54.

Stuben J. and Sterman J.D. (2008), Transition Challenges for Alternative Fuel Vehicles and Transportation Systems, Environment and Planning B: Planning and Design, 35(6), 1070-1097.

Thiel C., Perujo A. and Mercier A. (2010), Cost and $\mathrm{CO}_{2}$ aspects of future vehicle options in Europe under new energy policy scenarios, Energy Policy, 38(11), 7142-7151.

TTS. (2006). Data Management Group: Transportation Tomorrow Survey 2006. Retrieved 2012 Nov. from Joint Program in Transportation, University of Toronto: http://www.dmg.utoronto.ca// 
List of abbreviations

\begin{tabular}{cc}
\hline \hline LEDU & $\begin{array}{r}\text { Total population by lowest level of education (including high school certificate, } \\
\text { college or other non-university certificate or diploma) }\end{array}$ \\
INC & $\begin{array}{c}\text { A dummy variable; when Household income is under } \$ 30000=1 ; \text { when } \\
\text { Household income is under } \$ 80000=2 ; \text { when Household income is above } \\
\$ 80000=3 ;\end{array}$ \\
SEN & Total number of seniors over 65 years \\
PWSCT & Usual place of work ( same census subdivision of residence) \\
SINPAR & Total lone-parent families \\
CWCHILD & Married couples With children at home \\
UNEMP & Unemployed per cencus tract \\
ODWE & Total number of Owned dwellings \\
DDWE & Total number of apartments/duplexes \\
NPPCF & Average number of persons per census family \\
HEV & Hybrid Electric Vehicles \\
EV & Electric Vehicles \\
\hline
\end{tabular}

